\title{
Responsible Variables in Discriminating Bangladeshi Adult Patients of Hypertensive Retinopathy from other Adults \\ K.C.Bhuyan
}

Professor, [Retired] of Statistics, Jahangirnagar University, Dhaka, Bangladesh.

*Corresponding Author: K.C.Bhuyan, Professor, [Retired]of Statistics, Jahangirnagar University, Dhaka, Bangladesh.

\section{Abstract}

The information presented here were analytical results of data collected from 950 adults of ages 18 years and above residing in a semi-urban area of Bangladesh to identify the variables responsible for the prevalence of hypertension and retinopathy simultaneously among the adults. Out of 950 respondents $5.3 \%$ were hypertensive and $70.0 \%$ of them were suffering from retinopathy also. The sample hypertensive retinopathy patients were 3.7\%. This health problem did not vary significantly with the variation of residence, religion, marital status, economic variation, body mass index, and sedentary activity of the adults. But males, non-Muslims, married persons, adults of lowest economic activities, underweight adults and adults involved in sedentary activity had higher risk of facing this health problem. Over age, illiteracy, non-involvement in any recognized work, physical inactivity, process food consumption, prevalence of diabetes, longer duration of diabetes and hypertension were significantly the higher risk factors for the prevalence of hypertensive retinopathy. The risk ratios for these levels of variables were 10.94, 5.61, 5.75, 2.42, .48, 2.19, 3.29, and 1.19 times respectively as these were for other adults. However, the most responsible variable was duration of hypertension followed by age, education, duration of diabetes, process food consumption, etc. These were identified by discriminant analysis.

Keywords : Hypertension, Retinopathy, Socioeconomic variable, Responsible variable, Risk ratio, Discriminant analysis.

\section{INTRODUCTION}

Hypertension in association with obesity and diabetes can lead to severe health hazard worldwide [ 1, 2 ]. These three non-communicable diseases increase the risk of heart disease, stroke, chronic kidney disease, disability, retinopathy, target organ damage, and sometimes death [ 3 - 18]. Retinopathy is one of the target organ damage due to high blood pressure and it is one of the deadliest disease in the eye and this problem is known as hypertensive retinopathy [11]. But, hypertension is the major cause of premature death worldwide [ 19 ]. Number of adults with hypertension increased from 594 million in 1975 to 1.13 billion in 2015. The increase was noted largely in low-and middle-income countries. Around 7.5 million deaths or $12.8 \%$ of the total of all deaths worldwide occur due to high blood pressure [ 20 ]. It is predicted to be increased to 1.56 billion adults with hypertension in 2025 [ 21 ]. Thus worldwide death is also expected to be increased due to hypertensive retinopathy. The causes of hypertensive retinopathy are age, duration of hypertension, smoking habit, family history of hypertension, elevated blood pressure, longer duration of diabetes and obesity [6-7, 21 -24]. Mild hypertensive retinopathy was observed among non-diabetic adults also and in one study it was noted that $10 \%$ non-diabetic adults were affected by hypertensive retinopathy [ 25 - 27]. Retinopathy occurs due to prolonged diabetes, and uncontrolled blood glucose[ 28 - 31]. Retinopathy was also observed among older people without diabetes [27 ]. It happens when high blood sugar levels damage blood vessels in the retina and it starts due to uncontrolled blood sugar and delayed treatment of diabetes and it is the second largest non-communicable disease among human beings [31-32]. 
Responsible Variables in Discriminating Bangladeshi Adult Patients of Hypertensive Retinopathy from other Adults

The statement mentioned above were noted in hypertensive adults. Predictors for Bangladeshi adults were also mentioned [ 33 ]. It was reported that eldest age group was a risk factor for hypertension [ 33] ]. But, regular physical activity and diet control can reduce the blood pressure, blood sugar, body weight and hence can reduce the hypertension and its associated health problem [ 34 - 37]. Moreover, some socioeconomic variables or a particular level of a variable may not create the problem of hypertension in all types of subjects [38 - 40]. Thus an attempt was made to identify some socioeconomic variables responsible for prevalence of hypertensive retinopathy among Bangladeshi adults of 18 years and above.

\section{Methodology}

For this analysis the data were collected from adults of ages 18 years and above residing in a semi-urban area where both urban and rural facilities were prevailed. The adults were investigated using quota sampling plan to cover males and females in the ratio 50.1:49.9 [41]. The respondents were investigated by some medical technologists during the session 2018 - 19 by direct interview. The total investigated units were 950 and information were recorded from them through a pre-designed and pre-tested questionnaire. The questionnaire contained questions related to different socioeconomic variables of the respondents and of the families. Maximum questions were related to different socio-demographic variables of the respondents and of their lifestyle, specifically their personal food habit, working habit, physical activity, utilization of time, prevalence of any non-communicable disease viz. eye problem, kidney problem, heart problem, blood pressure, blood sugar, treatment stage of disease, admission into hospital, duration of disease and treatment stage of the disease. Beside these variables, information on family income and family expenditure were also recorded. The value of each of the variable was noted in nominal scale.

The respondents were classified into 4 categories according to their body mass index ( BMI). Body mass index was measured from the information of weight ( in kg) divided by height ( in metre ${ }^{2}$ ) The categories of the investigated subjects were underweight ( if BMI $<18.5$ ), normal( $18.5 \leq \mathrm{BMI},<23$ ), overweight ( 23 $\leq \mathrm{BMI}<27.5$ ) and obese ( $\mathrm{BMI} \geq 27.5$ ) [42-43]. They were also divided into 4 groups according to their blood pressure level ( $\mathrm{mmHg}$ ). The 4 groups were identified as optimal ( $\mathrm{BP}<120 / 80$ ), normal ( $\mathrm{BP}<130 / 85$ ), high normal $(\mathrm{BP}<140 / 85)$ and hypertensive $(\mathrm{BP} \geq$ 140/90) [34, 44]. The adults were also classified into 2 groups; in one group there were 35 hypertensive retinopathy patients and in another group there 915 were other adults.

To fulfil the objective of the study, association of any of the socioeconomic variables with prevalence of hypertensive retinopathy was examined. Significant association was decided if probability of any Chisquare test statistic used for observing association $\leq 0.05$. Irrespective of significant or insignificant association the risk ratio [R.R ] in favour of a higher group (in percentage) of any of the variables along with $95 \%$ confidence interval of R.R was calculated. Finally, discriminant analysis [ $45-47$ ] was done to discriminate hypertensive retinopathy patients from other investigated adults to identify the important variables for this discrimination. Statistical calculation was done using SPSS version 25.

\section{RESULTS}

The sample contained 950 adults, out of which 50 were hypertensive and $70 \%$ of them were suffering form retinopathy also [Table 1]. The total retinopathy patients were 178 in the sample. Beside retinopathy patients, there were another $32.2 \%$ adults of other diseases. The different health hazards were significantly associated with level of hypertension [ $\chi=139.385, \mathrm{p}-$ value $=0.000]$.

Table 1. Classification of adults according to health hazard and level of hypertension

\begin{tabular}{|c|c|c|c|c|c|c|c|c|c|c|}
\hline \multirow{3}{*}{$\begin{array}{l}\text { Health } \\
\text { hazard }\end{array}$} & \multicolumn{6}{|c|}{ Level of hypertension } & & & \multicolumn{2}{|l|}{\begin{tabular}{|l|} 
Total \\
\end{tabular}} \\
\hline & \multicolumn{2}{|l|}{ Optimal } & \multicolumn{2}{|l|}{ Normal } & \multicolumn{2}{|c|}{ High normal } & \multicolumn{2}{|c|}{ Hypertensive } & \multirow{2}{*}{ Number } & \multirow{2}{*}{$\%$} \\
\hline & Number & $\%$ & Number & $\%$ & Number & $\%$ & Number & $\%$ & & \\
\hline None & 295 & 58.2 & 143 & 44.1 & 26 & 37.7 & 2 & 4.0 & 466 & 49.1 \\
\hline Heart & 50 & 9.9 & 63 & 19.4 & 14 & 20.3 & 5 & 10.0 & 132 & 13.9 \\
\hline Eye & 85 & 16.8 & 46 & 14.2 & 12 & 17.4 & 35 & 70.0 & 178 & 18.7 \\
\hline Kidney & 28 & 5.5 & 41 & 12.7 & 10 & 14.5 & 6 & 12.0 & 85 & 8.9 \\
\hline Others & 49 & 9.7 & 31 & 9.6 & 7 & 10.1 & 2 & 4.0 & 89 & 9.4 \\
\hline Total & 507 & 53.4 & 324 & 34.1 & 69 & 7.3 & 50 & 5.3 & 950 & 100.0 \\
\hline
\end{tabular}


Responsible Variables in Discriminating Bangladeshi Adult Patients of Hypertensive Retinopathy from other Adults

The percentage of rural adults was 68.7 and 3.8\% of them were patients of hypertensive retinopathy as against the overall prevalence rate of $3.7 \%$ in the sample. The rural respondents had $14 \%$ more risk of affecting by the aforementioned non-communicable disease [ R.R. $=1.14$, C.I. $(0.55,2.34]$. But prevalence of hypertensive retinopathy did not vary significantly with the variation of residence of the respondents [ $\chi^{2}=1.230, \mathrm{p}$-value $=0.726$; Table 2]. The nonMuslim respondents were $15.5 \%$ in the sample. But $6.1 \%$ of them were suffering from hypertension and retinopathy simultaneously. For this group the chance of prevalence of the disease was 1.89 times as it was for Muslim respondents [ R.R. $=1.89$,C.I.( $0.90,2.47)]$. However, religion was independent of this health hazard $\left[\chi^{2}=2.914, \mathrm{p}\right.$-value $=0.088$ ].Prevalence rate among males (50.1\%) was 4.0 and they were $18 \%$ more exposed to this health problem[ R.R. $=1.18$,C.I. $(0.61,2.27)\}$, though gender variation and prevalence of hypertensive retinopathy were not significantly associated $\left[\chi^{2}=0.254, \mathrm{p}\right.$-value $\left.=0.614\right]$. Similar insignificant relationship was observed for adults of different marital status, but married persons ( $90.0 \%$ ) had 3.78 times chance of affecting by this health hazard $\left[\chi^{2}=2.060, \mathrm{p}\right.$-value $=0.151$; R.R... $=3.78$, C.I. $(0.52,27.30]$. The prevalence rate in married persons was $4.0 \%$ against $1.1 \%$ rate in single adults. There were $9.8 \%$ elderly people in the sample and $20.4 \%$ of them were suffering from hypertensive retinopathy. The prevalence rate was significantly increasing with the increase in ages of the adults [ $\chi^{2}=87,525, p-$ value $\left.=0.000\right]$. For elderly people the chance of prevalence was 10.94 times as it was for others [ R.R. $=10.94$, C.I. $(5.83,20.52)]$.

The illiterate adults in the sample was $11.8 \%$ and $13.4 \%$ of them were affected by prevalence of hypertensive retinopathy. This prevalence rate was significantly higher than the overall prevalence rate in the sample adults $\left[\chi^{2}=34.856, p-\right.$ value $\left.=0.000\right]$. The prevalence rate was decreasing with the increase in level of education of the respondents. The chance of prevalence was 5.61 times for illiterate persons as it was in educated persons [R.R.=5.61, C.I.(2.96,10.63)]. There were $8.3 \%$ respondents who were either inactive or unable to work due to old age. The prevalence rate among them was $15.2 \%$ and this rate was significantly higher compared to the rates in other professionals $\left[\chi^{2}=36.676, \mathrm{p}\right.$-value $\left.=0.000\right]$.
For this group the risk of prevalence was 5.75 times as it was in other professionals [ R.R. $=5.75$, C.I. $(2.98$, 11.11)]. The lowest prevalence rate (0.005) was noted among servicepersons ( $22.8 \%$ ). The rate (4.5\%) was also higher among farmers ( $13.9 \%)$. Among the respondents $52.6 \%$ were involved in physical work. They were least affected group in respect of facing the problem of hypertension and retinopathy simultaneously. For them the prevalence rate was 0.022 . There were $7.8 \%$ elderly people who were physically unable to work. Among them the prevalence rate was 0.054 . The prevalence rate for physically inactive group was significantly higher $\left[\chi^{2}\right.$ $=6.554, \mathrm{p}$-value $=0.038]$. For inactive group the risk of prevalence was 2.42 times as it was for physically active adults [ R.R. $=2.42$, C.I. $(1.20,4.88)]$. Watching television, gossiping with friends and relatives over telephone and reading newspapers are used as a mode of passing leisure time by many adults. These works are termed as sedentary activity. In the sample $59.2 \%$ adults were involved in sedentary activity. For them the prevalence rate of hypertensive retinopathy was 0.044 . This rate was higher as it was in the sample adults, but it was not significantly higher $\left[\chi^{2}=2.265\right.$, $\mathrm{p}-$ value $=0.132]$. For them the chance of prevalence was 1.73 times as it was for others [ R.R. $=1.73$, C.I. $(0.84,3.54)]$.In the sample $11.7 \%$ adults were from families of lowest income group. For them the prevalence rate was 0.054 . This rate was decreasing , but not significantly, with the increase in family income [ $\chi^{2}=2.472, p$-value $\left.=0.480\right]$. The chance of prevalence for adults of families of lowest income group was 1.56 times as it was for others [R.R.=1.56, C.I.( 0.66,3.67)]. The percentage of adults coming from the families spending lowest amount of money was 25.6 and $5.4 \%$ of them were the patients of hypertensive retinopathy. For them the risk was $94 \%$ more compared to the risk of other adults [R.R. $=1.94$, C.I.(1.01,3.76)]. The risk was significantly increasing with the increase in level of family expenditure $\left[\chi^{2}\right.$ $=6.24, \mathrm{p}-$ value $=00.010]$. There were $50.2 \%$ adults habituated in taking process food and $5.2 \%$ of them were suffering from hypertensive retinopathy. For them the chance of prevalence was 2.48 times as it was for others [R.R.=2.48, C.I.(1.21,5.10)]. Habit of taking process food was significantly associated with prevalence of this health hazard [ $\chi^{2}=6.544, p$ -value $=0.011]$. There were $52.1 \%$ non-smokers, but $5.1 \%$ of them were affected by the prevalence of hypertensive 
Responsible Variables in Discriminating Bangladeshi Adult Patients of Hypertensive Retinopathy from other Adults

Table 1. Distribution of adults according to prevalence of hypertensive retinopathy and socioeconomic variables

\begin{tabular}{|c|c|c|c|c|c|c|}
\hline \multirow{3}{*}{ Socioeconomic variables } & \multicolumn{4}{|c|}{ Prevalence of hypertensive retinopathy } & \multirow{2}{*}{\multicolumn{2}{|c|}{ Total }} \\
\hline & \multicolumn{2}{|c|}{ Yes } & \multicolumn{2}{|c|}{ No } & & \\
\hline & Number & $\%$ & Number & $\%$ & Number & $\%$ \\
\hline \multicolumn{7}{|l|}{ Residence } \\
\hline Rural & 25 & 3.8 & 628 & 96.2 & 653 & 68.7 \\
\hline Urban & 10 & 3.4 & 287 & 96.6 & 297 & 31.3 \\
\hline Total & 35 & 3.7 & 915 & 96.3 & 950 & 100.0 \\
\hline \multicolumn{7}{|l|}{ Gender } \\
\hline Male & 19 & 4.0 & 457 & 96.0 & 476 & 50.1 \\
\hline Female & 16 & 3.4 & 458 & 96.6 & 474 & 49.9 \\
\hline \multicolumn{7}{|l|}{ Religion } \\
\hline Muslim & 26 & 3.2 & 776 & 96.8 & 803 & 84.5 \\
\hline Non-Muslim & 9 & 6.4 & 138 & 93.6 & 147 & 15.5 \\
\hline \multicolumn{7}{|l|}{ Marital status } \\
\hline Currently married & 34 & 4.0 & 821 & 96.0 & 855 & 90.0 \\
\hline Currently single & 1 & 1.1 & 94 & 98.9 & 95 & 10.0 \\
\hline \multicolumn{7}{|l|}{ Age (in years) } \\
\hline$<25$ & 0 & 0.0 & 42 & 100.0 & 42 & 4.4 \\
\hline $25-40$ & 0 & 0.0 & 159 & 100.0 & 159 & 16.7 \\
\hline $40-50$ & 3 & 1.0 & 304 & 99.0 & 307 & 32.3 \\
\hline $50-60$ & 13 & 3.7 & 336 & 96.3 & 349 & 36.7 \\
\hline $60^{+}$ & 19 & 20.4 & 74 & 79.6 & 93 & 9.8 \\
\hline \multicolumn{7}{|l|}{ Education } \\
\hline Illiterate & 15 & 13.4 & 97 & 86.6 & 112 & 11.8 \\
\hline Primary & 7 & 3.3 & 208 & 96.7 & 215 & 22.0 \\
\hline Secondary & 7 & 2.7 & 249 & 97.3 & 256 & 26.9 \\
\hline Higher & 6 & 1.6 & 361 & 98.4 & 367 & 38.6 \\
\hline \multicolumn{7}{|l|}{ Profession } \\
\hline Agriculture & 6 & 4.5 & 126 & 95.5 & 132 & 13.9 \\
\hline Business & 6 & 3.2 & 183 & 96.8 & 189 & 19.9 \\
\hline \begin{tabular}{|l|} 
Service \\
\end{tabular} & 1 & 0.5 & 216 & 99.5 & 217 & 22.8 \\
\hline Housewife & 10 & 3.0 & 323 & 97.0 & 333 & 35.1 \\
\hline Others & 12 & 15.2 & 67 & 84.8 & 79 & 8.3 \\
\hline \multicolumn{7}{|l|}{\begin{tabular}{|l|} 
Physical labor \\
\end{tabular}} \\
\hline Yes & 11 & 2.2 & 489 & 97.8 & 500 & 52.6 \\
\hline No & 20 & 5.3 & 356 & 94.7 & 376 & 39.6 \\
\hline Unable to work & 4 & 5.4 & 70 & 94.6 & 74 & 7.8 \\
\hline \multicolumn{7}{|l|}{ Income ( 000 taka ) } \\
\hline$<50$ & 6 & 5.4 & 105 & 94.6 & 111 & 11.7 \\
\hline $50-100$ & 20 & 4.1 & 466 & 95.9 & 486 & 51.2 \\
\hline $100-150$ & 4 & 2.4 & 160 & 97.6 & 164 & 17.3 \\
\hline $150^{+}$ & 5 & 2.6 & 184 & 97.4 & 189 & 19.9 \\
\hline \multicolumn{7}{|c|}{ Family expenditure ( in 000 taka) } \\
\hline$<50$ & 14 & 5.8 & 229 & 94.2 & 243 & 25.6 \\
\hline $50-100$ & 14 & 3.6 & 378 & 96.4 & 392 & 41.3 \\
\hline $100-150$ & 6 & 3.3 & 177 & 96.7 & 183 & 19.3 \\
\hline $150^{+}$ & 1 & 0.8 & 131 & 99.2 & 132 & 13.9 \\
\hline \multicolumn{7}{|l|}{ Smoking habit } \\
\hline Yes & 10 & 2.2 & 445 & 97.8 & 455 & 47.9 \\
\hline
\end{tabular}


Responsible Variables in Discriminating Bangladeshi Adult Patients of Hypertensive Retinopathy from other Adults

\begin{tabular}{|l|c|c|c|c|c|c|}
\hline \hline No & 25 & 5.1 & 470 & 94.9 & 495 & 52.1 \\
\hline Habit of taking process food & & & & & & \\
\hline Yes & 25 & 5.2 & 452 & 94.8 & 477 & 50.2 \\
\hline No & 10 & 2.1 & 463 & 97.9 & 473 & 49.8 \\
\hline Utilization of time & & & & & & \\
\hline Sedentary activity & 25 & 4.4 & 537 & 95.6 & 562 & 59.2 \\
\hline No & 10 & 2.5 & 378 & 97.5 & 388 & 40.8 \\
\hline Obesity & & & & & & \\
\hline Underweight & 4 & 6.6 & 57 & 93.4 & 61 & 6.4 \\
\hline Normal & 13 & 5.3 & 233 & 94.7 & 246 & 25.9 \\
\hline Overweight & 9 & 2.3 & 377 & 97.7 & 386 & 40.6 \\
\hline Obese & 9 & 3.5 & 248 & 96.5 & 257 & 27.1 \\
\hline Prevalence of diabetes & & & & & & \\
\hline Yes & 20 & 5.6 & 339 & 94.4 & 359 & 37.8 \\
\hline No & 15 & 2.5 & 576 & 97.5 & 591 & 62.2 \\
\hline Duration of diabetes (in years) & & & & & & \\
\hline Does not arise & 15 & 2.5 & 576 & 97.5 & 591 & 62.2 \\
\hline$<5$ & 4 & 3.4 & 112 & 96.6 & 116 & 12.2 \\
\hline $5-10$ & 5 & 3.7 & 130 & 96.3 & 135 & 14.2 \\
\hline $10-15$ & 6 & 8.0 & 69 & 92.0 & 75 & 7.9 \\
\hline $15^{+}$ & 5 & 15.2 & 28 & 84.8 & 33 & 3.5 \\
\hline Duration of hypertension (in years) & & & & & & \\
\hline Does not arise & 0 & 0.0 & 900 & 100.0 & 900 & 94.7 \\
\hline$<5$ & 0 & 0.0 & 1 & 100.0 & 1 & 0.3 \\
\hline $5-10$ & 8 & 80.0 & 2 & 20.0 & 10 & 0.9 \\
\hline $10-15$ & 10 & 62.5 & 6 & 37.5 & 16 & 1.4 \\
\hline $15^{+}$ & 17 & 73.9 & 6 & 26.1 & 23 & 2.7 \\
\hline Total & 35 & 3.7 & 915 & 96.3 & 950 & 100.0 \\
\hline
\end{tabular}

retinopathy. This proportion of affected adults was significantly higher in comparison to the proportion of affected smoker adults [ $\chi^{2}=5.437, \mathrm{p}$-value $\left.=0.020\right]$. The non-smokers had 2.30 times risk compared to the risk of smoker adults [ R.R. $=2.30$, C.I.(1.12, 4.73)].

The percentage of diabetic adults was 37.8 and $5.6 \%$ of them were suffering from hypertensive retinopathy. Some of them $(3.5 \%)$ were suffering for 15 years and above, prevalence rate in them was 0.739 . The average suffering was 6 years with standard deviation of 6.68 years. With the increase in duration of diabetes the prevalence rate was significantly increased $\left[\chi^{2}=\right.$ 18.372, $\mathrm{p}$-value $=0.001]$. The risk of prevalence for patients suffering for longer duration was 3.29 times as it was for others [R.R. $=3.29$, C.I. $(1.28,8.48)]$. This risk was 2.19 times among diabetic patients compared to that of non-diabetic adults[ R.R.=2.19, C.I.(1.14,4.22)]. Prevalence of hypertensive retinopathy were significantly dependent on prevalence of diabetes [ $\chi^{2}=5.790, p-$ value $\left.=0.016\right]$. Another significantly influencing variable of the prevalence was duration of hypertension $\left[\chi^{2}=674.254, \mathrm{p}=00\right]$. The hypertensive adults suffering for 15 years and above was $46.0 \%$ and hypertensive retinopathy was prevailed in $73.9 \%$ of them. This group was $2.7 \%$ in the sample. Only $0.9 \%$ adults were suffering from hypertension for 5 10 years and the prevalence rate of this health hazard among them was 0.8 . For them the risk was 1.19 times as it was for others [ R.R. $=1.19$, C.I. $(0.82,1.73)]$. The average suffering from this health hazard was 13.79 years with standard deviation of 4.08 years.

\section{DisCRIMINANT ANALYSIS}

The above presented results indicated that age, education, profession, physical labour, process food consumption, duration of diabetes and duration of hypertension were significantly associated with prevalence of hypertensive retinopathy. But according to the objective of the study, we need to identify some variables to discriminate the hypertensive retinopathy patients from other adults under study. For this, discriminant analysis was performed using the variables residence, religion, gender, marital status, age, education, profession, family income, 
Responsible Variables in Discriminating Bangladeshi Adult Patients of Hypertensive Retinopathy from other Adults

family expenditure, physical labour, smoking habit, process food consumption, utilization of time, body mass index, prevalence of diabetes, duration of diabetes and duration of hypertension. These variables were sufficient to discriminate between two groups of adults as was observed by Chi-square test, where the results of the test were $\Lambda=0.361$, $\chi^{2}=957.904, \mathrm{p}$-value $=0.000$. The variables age, education, profession, physical labour, smoking habit, process food consumption, prevalence of diabetes , duration of diabetes and duration of hypertension were significantly different for two groups of adults. The results were shown in Table 3. The most important variable for discrimination was decided by the highest absolute value of correlation coefficient ( $r$ ) between discriminant function score and variable. The most important variable was duration of hypertension followed by age, education, duration of diabetes, process food consumption, prevalence of diabetes, etc.

Table 3. Results of discriminant analysis

\begin{tabular}{|l|l|l|l|l|l|}
\hline Variables & Wilk's $\Lambda$ & F & P -value & Discriminant function coefficient & r \\
\hline Duration of hypertension & 0.374 & 1584.174 & 0.000 & 1.017 & 0.971 \\
\hline Age & 0,933 & 68.572 & 0.000 & 0.087 & 0.202 \\
\hline Education & 0.977 & 22.582 & 0.000 & -0.065 & -0.116 \\
\hline Duration of diabetes & 0.983 & 16.518 & 0.000 & -0.233 & 0.099 \\
\hline Process food consumption & 0.993 & 6.576 & 0.010 & -0.015 & 0.063 \\
\hline Prevalence of diabetes & 0.994 & 5.813 & 0.016 & -0.163 & -0.059 \\
\hline Physical labour & 0.994 & 5.584 & 0.018 & -0.134 & 0.058 \\
\hline Smoking habit & 0.994 & 5.457 & 0.020 & 0.028 & 0.057 \\
\hline Profession & 0.995 & 4.815 & 0.028 & 0.048 & 0.054 \\
\hline Family expenditure & 0.997 & 3.286 & 0.070 & -0.039 & -0.044 \\
\hline Religion & 0.997 & 2.916 & 0.088 & 0.080 & 0.042 \\
\hline Family income & 0.997 & 2.757 & 0.097 & -0.017 & -0.041 \\
\hline Body bass index & 0.997 & 2.621 & 0.106 & -0.090 & -0.039 \\
\hline Utilization of time & 0.998 & 2.265 & 0.133 & -0.078 & 0.037 \\
\hline Marital status & 0.998 & 2.060 & 0.152 & 0.013 & -0.035 \\
\hline Gender & 1.000 & 0.254 & 0.615 & 0.019 & -0.012 \\
\hline Residence & 1.000 & 0.122 & 0.727 & 0.090 & -0.009 \\
\hline
\end{tabular}

\section{Discussion}

Hypertension is a relatively easy preventable disease which is associated with other non-communicable diseases, such as diabetes, kidney diseases, nerve damage, eye problem, overactive thyroid gland, sleep apnoea, pregnancy, obesity, etc. [ 48 - 50 ]. The eye problem in presence of hypertension, obesity and diabetes was noted in both home and abroad [ 13 - 15, 51-52]. In earlier studies it was observed that prevalence of diabetes, duration of diabetes, being females, old age, physically inactivity, blood pressure were the risk factors for prevalence of retinopathy. In this paper an attempt was made to identify some important variables responsible for retinopathy when adults were suffering from high blood pressure also.
For this, 950 adults of ages 18 years and above were investigated. Among the adults, there were $68.7 \%$ rural people, $50.1 \%$ males, $15.5 \%$ non-Muslims and $90.0 \%$ married persons. For each of these 4 categories of adults the prevalence rate of hypertensive retinopathy was higher than the prevalence rate for the overall sample adults. This overall rate was 3.7.. This rate was 0.7 among the $5.3 \%$ hypertensive adults. None of the prevalence rate mentioned above was significantly different from the overall prevalence rate. But for all of these categories of adults the risk of prevalence was higher compared to the risk of their counterparts. Like other study [14], the old age was the risk factor for the prevalence of hypertensive retinopathy. For elderly people the risk was 10.94 times as it was for adults of other ages. The prevalence rate was increasing with 
Responsible Variables in Discriminating Bangladeshi Adult Patients of Hypertensive Retinopathy from other Adults

the increase in ages of adults. Illiteracy was the risk factor for the prevalence. For illiterate people the risk of prevalence was 5.61 times than it was for others. With the increase in level of education the prevalence rate was significantly decreasing. Similar result was observed in another study [53]. Lower economy was also the risk factor for prevalence. The adults belonged to lower economic group of families had higher risk of prevalence. This phenomenon was noted in other study also [53].

In many studies, lifestyle factor including physical inactivity was identified as the risk factor for many non-communicable diseases [ 36-38, 51-52]. This study also indicated that physical inactivity was the risk factor for prevalence of hypertensive retinopathy. For physical inactive group the risk was 2.42 times as it was for others. The risk was also higher for process food consumers and adults involved in sedentary activity. However, the risk of prevalence was not prominent for smokers.

Usually, obesity is the cause of many noncommunicable diseases [36 -38].In other studies it was noted that obesity was the cause of retinopathy and diabetic retinopathy [51-52]. But this study did not provide information of association between obesity and prevalence of hypertensive retinopathy. However, diabetes and duration of diabetes were the risk factors for the prevalence of this health hazard. Diabetic patients suffering for longest duration had 3.29 times risk of prevalence compared to the risk of other diabetic patients. Longer duration of hypertension was the risk factor for the prevalence of hypertensive retinopathy. This phenomenon was also observed in other studies $[12,14]$.

Finally, the study indicated that the most responsible variable for hypertensive retinopathy was duration of hypertension followed by age, education. duration of diabetes, consumption of process food, prevalence of diabetes, physical inactivity, etc.

\section{ConCLUSION}

The study was conducted to identify some socioeconomic variables responsible for hypertensive retinopathy among Bangladeshi adults of 18 years and above. For this, data were collected from 950 adults covering both males and females residing in both urban and rural areas. The sample adults suffering from hypertensive retinopathy was 3.7\%. They were $70 \%$ of hypertensive adults ( $5.3 \%$ ) in the sample. Rural people(3.4\%), urban people (3.4\%) males (3.8\%), females (3.4\%), Muslims (3.2\%), non-Muslims $(6.4 \%)$, married $(4.0 \%)$ and single $(1.1 \%)$ adults were not significantly different in rates of prevalence of the disease under study. But, non-Muslims ( 1.89) and married persons (3.78) had higher risk of prevalence. Higher risk was also observed for people of lowest economy ( 1.56) and physically inactive adults (2.42). Significantly higher risk was observed among elderly people( 10.94), lower educated people (5.61), process food consumers (2.48), adults involved in sedentary activity (1.73), diabetic adults ( 2.19 ), adults suffering from diabetes for 15 years and above (3.29) and hypertensive adults of 5 - 10 years duration (1.19). The discriminant analysis identified duration of hypertension as the most responsible variable for the prevalence of hypertensive retinopathy. The other responsible variables, in order of weight, were age, education, profession, duration of diabetes, consumption of process food, prevalence of diabetes, physical inactivity, etc.

Due to upward social and economic mobility in the society and in the country; obesity, hypertension and diabetes cannot be avoided. These three health hazards are the source of other non-communicable diseases including retinopathy, cardiovascular diseases, kidney diseases, etc. So, attention should be focused to control the negative effects of hypertension and diabetes. For this, people should be advised to follow some guide lines to maintain healthy life. These are

(i) Avoiding first food, excessive salt and high fatty food and sugar-based food, and try to develop the habit of taking home made food as per as possible,

(ii) Engaging in any type of physical work and physical exercise,

(iii) Developing habit of walking whenever it is possible,

(iv) Avoiding sedentary activity as per as possible

(v) Controlling body weight,

(vi) Consulting doctor whenever it is necessary,

(vii) Trying to maintain the blood sugar level and blood pressure level below danger level,

(viii) Avoiding smoking and drinking alcohol. 
Responsible Variables in Discriminating Bangladeshi Adult Patients of Hypertensive Retinopathy from other Adults

Government health service providers with the assistance of rural and urban social workers can do a lot to encourage the people to lead healthy life.

\section{REFERENCES}

[1] Erem, C.; Hacihasanoglu, A.; Kocak, M.; Deger, O.; Topbas, M: Prevalence of pre-hypertension and hypertension and associated risk factors among Turkish adults: Trabzon hypertension study, Journal of Public Health, 2009, 31(1), 47 - 58. doi: 10.1093/pubmedfdn078.

[2] Ahmed, A.; Rahaman, M.; Hasan , R.; Shima, S.; Faruquee, M.H. ; Islam, T and Emdadul, S.: Hypertension and associated risk factors in some selected rural areas of Bangladesh, International Journal of Research in Medical Sciences, 2014, 2(3), p925. doi:10.545523206012.ijrms20140816.

[3] Branda, B.S.: Medical News Today.2019

[4] Cihangir, E. ; Arif, H. ; Mustafa, K.; Orhan, D. and Murat, T. : Prevalence of prehypertension and hypertension and associated factors among Turkish adults: Trabzon Hypertension Study, Jour Pub Health, 2008, 31(1), 4 - 58. doi: 10.1093/ pubmed/fdn078.

[5] WHO : Hypertension: World Health Organization, Financial Report, 2019

[6] Sikha, S. ; Ravi, S. and Singh, G.P.: Prevalence and associated risk factors of hypertension; A cross-sectional study in urban Varanasi, Int Jour Hypertens, 2017, 5491838.

[7] Chobanian, A.V.; Bakris, G.L. ; Black, H.R.; Cushman, W.C. et al : Seventh Report of the Joint National Committee on Prevention, Detection, Evaluation and Treatment of High Blood Pressure, Hypertension, 2003, 42(6), 1206 - 1252. Epub 2003, Dec 1.

[8] Keamy, P.M; Whelton, M.; Reynolds, K. et al : Worldwide prevalence of hypertension : a systematic review, Jour Hypertens.,2004,22, 11 - 19.

[9] Suneel, V.; Ivana, L. and Bakris, G.L.(2010): Epidemiology of hypertensive kidney disease, Nature Review,s Nephrology, 7, 11 -21.

[10] Hill, G.S.(2008): Hypertensive nephrosclerosis, Curr Opin Nephrol Hypertens, 17, 266 -270.
[11] Grosso, A.; Veglio, F.;Porta, M.; Grignolo, F.M. and Yong, T.Y. ( 2005): Hypertensive retinopathy revisited : some answers , more questions, British Jour Ophthalmology, 89(2).

[12] Zhang, Y.; Zhao, L.; Li, H and Wang, Y.( 2019): Risk factors for hypertensive retinopathy in a Chinese population with hypertension: The Beijing Eye Study, 17(1), 453 - 458.

[13] Strejjewski, T.P.; Papakostas, T.D. and Vavvas, D.(2016): Proliferative hypertensive retinopathy, JAMA, Ophthamal, 134, 345 - 346.

[14] Erden, S. and Bicakci, E.( 2012); Hypertensive retinopathy ; incidence, risk factors and comorbidities , Clin Exp Hypetens, 3496), 397 - 401.

[15] Schmieder, R.E.(2009):Hypertensive retinopathy, Ophthalmologica, 18, 233 - 234.

[16] [16] Mondal, R.N.; Matin, M.A. ; Rani, M. and Hossain, M.Z.; Amaresh, C.S.; Singh, R.B..; Islam, F.M. and Das, A. ( 2017): Prevalence and risk factors of hypertensive retinopathy in hypertensive patients, Jour Hypertens , 6(2), DOI: 10.41722187 - 1095.1000241.

[17] Gudmundsdottir,H.; Taarnh $\phi$ j, N.C.C.B.; Strand, A.H. ; Kjeldsen, S.E..; $\mathrm{H} \phi$ ieggen, et al (2010): Blood pressure development and hypertensive retinopathy : 20 years follow-up of middleaged normotensive and hypertensive men, Jour Human Hypertens, 24, 505 - 513.

[18] Gupta, R.P.; Gupta, S.; Gahlot, A.; Dhaval, S. and Vashi, J. ( 2013): Evaluation of hypertensive retinopathy in patients of essential hypertension with high serum lipids, Medical Journal of Dr. D.Y. Patil Vidyapeeh, 6(2), 165 - 169.

[19] Mendis, S. : Global status report on noncommunicable diseases, Tech Rep WHO 2010.

[20] Tabrizi, J.S.; Sadeghi- Bazargani, M.; Farahbakhsh, L.N. and Nikniaz, Z. : Prevalence and associated factors of prehypertension and hypertension in Iranian population: the lifestyle promotion project (LPP), PLoS One,2016, 11(16), Article ID e0165264.

[21] Vasan, R.S.; Beiser, A.;Seshadri, S.; Latson, M.G.; Kannel, W.B.; D' Agostino, R.B. and Lovy, D.: Residuallifetimerisk for developing hypertension 
Responsible Variables in Discriminating Bangladeshi Adult Patients of Hypertensive Retinopathy from other Adults

in middle-aged women and men: The Framingham Heart Study, JAMA, 2002,287(8), 1003 - 1010.

[22] Jugal, K.; Gupta, N.; Kohli, C. and Kumar,N. : Prevalence of hypertension and determination of its risk factors in rural Delhi, Int Jour Hypertens, 2016, https://doi:org/10.1155/2016/7962 595.

[23] Everett, B and Zajacova, A. : Gender difference in hypertension and hypertension awareness among young adults, Biodemography and Social Biology, 2015,61(1), 1 - 17, doi: 10.1080/19485565.2014.929488.

[24] Wong, T.Y. and Mitchell, P.(2007): The eye in hypertension, Lancet, 369, 425 - 435.

[25] Bhargava, M.; Ikram, M.K. and Wong, T.Y.( 2011): How does hypertension affect your eyes? Jour Human Hypertens, 26(2), 71 - 83.

[26] Jaganathan, V. ; Cheung, N.; Tay, W.; Wang, J.; Mitchell, P. and Wong, T.(2010): Prevalence and risk factors of retinopathy in an Asian population without diabetes: the Singapore Malay Eye Study, Arch Ophthalmol 128, 40 -45.

[27] Yu, T.; Mitchel, P.; Berry, G.and Li, W Wang, J. j.C 1998): Retinopathy in older persons without diabetes and its relationship with hypertension, Arch Opthalmol, 116, 83 - 89.

[28] Klein,R.; Klein,B.R.;Moss,C.E.; Dvies,M.D.; DeMets, D.L. (1984): The Wisconsin Epidemiologic Study of Diabetic Retinopathy.iii Prevalence and risk of diabetic retinopathy when age at diagnosis is 30 or more years, Rch Opthalmol, 102, 527 - 532.

[29] Stratom, I.M.; Kohner, E.M.; Aldington, S.J.; Turner, R.C.; Holman, R.R.; Manley, S.E. and Mathews, D.R.( 2001): UKPDS 50: risk factors for incidence and progression of retinopathy in type ii diabetes over 6 years from diagnosis, Diabetologia, 44, 156 - 163.

[30] Ahmed, K.R.; Karim, M.N.; Bhomik, B. ;Habib, S.H. ; Bukht,M.S; Ali, L and Hussain, A. (2012): Incidence of diabetic retinopathy in Bangladesh: a 15 year follow-up study, J. Diabete,4 (4), 386 - 391.

[31] Dirani, M.; Xie, J.; Fenwick, E.; Benarous, R.; Rees, G.; Wong, T.Y.; Lamoureux, E.L. \{2011): Are obesity and anthropometry risk factors for diabetic retinopathy? The Diabetes Management Project, Clinical and Epidemiological research, 52(7).
[32] World Health Organization ( 1997): Global initiative for the elimination of avoidable blindness. An informal consultation, WHO/ PBL97 - 61.

[33] World Health Organization (2006): Consultation of Diabetes Mellitus, WHO.

[34] Rahaman,M,; Zaman,; Islam, J.Y.; Hasan, M.; Hossain,Z; Alam, B. and Tasmin, R. : Prevalence, treatment, patterns, and risk factors of hypertension and prehypertension among Bangladesh adults, Jou Hum Hypertens, 2017, 32, 334 - 348. https://doi.org/10.1038/s41371017-0018-x.

[35] Jessica, Y.I.;Zaman, M.M.; Haq, S.A.; Ahmed, S. and Al-Quadir ,Z. : Epidemiology of hypertension among Bangladeshi adults using the 2017 ACC/ AHA Hypertension Clinical Guidelines and Joint National Committee 7 Guideline, Jour Hypertens, 2018,32, $668-680$.

[36] Karar, Z.A.; Alam,N.; Streatfield, P.K. (2009): Epidemiological transition in rural Bangladesh, Global Health Action 19,2. doi: 10.3402/gha.V2 io ,1

[37] Bhuyan, K.C.( 2020): Socioeconomic variables responsible for exclusively diabetes among Bangladeshi adults, Acta Scientific Nutritional Health , 4(3), 2020, 1 - 6.

[38] https://doi.org/10.20431/2455-5983.0601002.

[39] Bhuyan, K.C. (2020): Factors responsible for prevalence of diabetes hypertension among Bangladeshi adults, Jour Dia Metabolism, 11.851,doi:10.35248/2155-6156.20.11.851

[40] Bhuyan, K.C. (2020): Identification of socioeconomic variables responsible for prevalence of hypertension among Bangladeshi adults, Jour Heart and cardiovascular Science, 1, 001-007, 2020.. Doi: 10.47755/j.Heart ardiovac Sci.

[41] Peltzer, K. and Supa, P.: The prevalence and social determinants of hypertension among adults in Indonesia: A cross-sectional population based study, Int Jour Hypertens, 2018, https:// doi. org/10.1155/2018/5610725.

[42] [ 40 ] Charles, A.: Rural and urban difference in blood pressure and hypertension in Ghana, West Africa, Public Health,2016, 120(6), 525 - 533. 
Responsible Variables in Discriminating Bangladeshi Adult Patients of Hypertensive Retinopathy from other Adults

[43] Bangladesh Bureau of Statistics (2018): Statistical Year Book of Bangladesh,2017, BBS, Dhaka, Bangladesh.

[44] AppropriateBody Mass Indexfor Asian Population and its Implications for Policy and Intervention Strategies, WHO Expert Consultation, Public Health, Lancet 363, 2004.

[45] Biswas, T.; Garnett, P. Sarah and Rawal, B.Lal ( 2017): The prevalence of underweight, overweight, and obesity in Bangladesh: Data from a national survey, PLoS One, 12(5), e0177395.

[46] Jan, A.S. ; Yan, Li.; Azusa, H.; KEI, A.; Eamon, D. and O'Brien, E. : Blood pressure measurement anno 2016. Amer Jour Hypertens, 2017, 30(5), 453 463.https://doi:org/10.1093/ajh/hpw 148.

[47] McLachlan, G.J. : Discriminant analysis and Statistical Pattern Recognition, Wiley Interscience, 2004, ISBN 978-0-471-69115-0.

[48] [46] Garson, G.D. : Discriminant function analysis. https://web.archive.org/web20080312065328, 2008.

[49] Bhuyan, K.C. : A note on the application of discriminant analysis in medical research, Archives of Diabetes and Obesity, 2019, 2(2),142 - 146.

[50] Burt, V.L. etal (1995): Prevalence of hypertension in the adult population, results from the third National Health and Nutrition Examination Survey, 1988- 1991, hypertension 5, 305 - 313.
[51] Bramlage, P.; Pittrow, D.; Wittchen, H.U.; Kirch, W.; Boehler, S.; Lehnort, H. etal (2004): Hypertension in overweight and obese primary care patients is highly prevalent and poorly controlled, Amer Jour Hypertension, 17, 904 - 910. doi:10.1016/j. amjhyper.2004.05.017.

[52] Vasan, R.s.; Beiser, A.; Seshadri, S.; Larson, M.G. ; Kannl, W.B.; D’Agostino, R.B. and Levy, D.( 2002): Residual lifetime risk for developing hypertension in middle-aged women and men : The Framingham Heart Study, JAMA, 287(8), $1003-1010$

[53] Bhuyan, K.C.(2020):Socioeconomic variables responsible for diabetic retinopathy among Bangladeshi adults, BJSTR,25(1), 18829-18836, doi: 10.26717/BJSTR.2020.25.004150.

[54] Bhuyan, K.C. ( 2020): Identification of risk factors of obesity retinopathy among Bangladeshi adults, Current Research of Diabetes and obesity Journal, 13(5), $0064 \quad-0071,555872 . D O I ; \quad 10.19080 /$ CRDOJ 2020.13.555872.

[55] Pun, C.B. and Tuladhar, S.(2019): Profile of hypertensive retinopathy in a tertiary centre in western Nepal, J-GMC-N, 12(1), 22 - 24.

Citation: K.C.Bhuyan. Responsible Variables in Discriminating Bangladeshi Adult Patients of Hypertensive Retinopathy from other Adults. Archives of Diabetes and Endocrine System. 2020; 3(2): 24-33.

Copyright: (c) 2020 K.C.Bhuyan. This is an open access article distributed under the Creative Commons Attribution License, which permits unrestricted use, distribution, and reproduction in any medium, provided the original work is properly cited. 